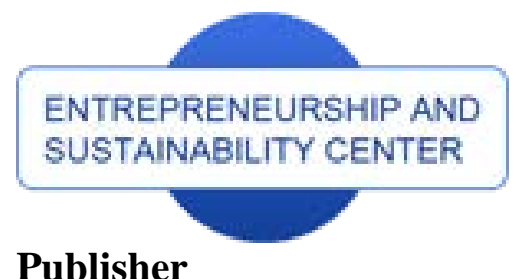

Publisher

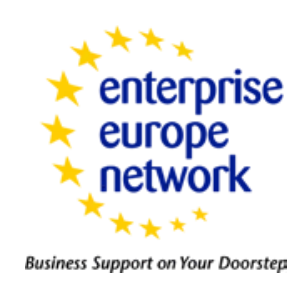

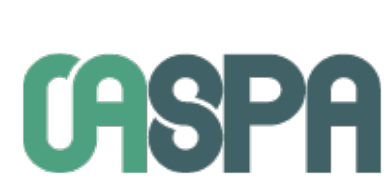

THOMSON REUTERS

Emerging Sources Citation Index WEB OF SCIENCE

\title{
UTILIZATION OF LABOUR RESOURCES THROUGH MATCHING PROFESSIONAL AND FAMILITY ROLES
}

\author{
Natalia Rimashevskaya ${ }^{1}$, Marina Malysheva ${ }^{2}$, Marina Pisklakova-Parker ${ }^{3}$ \\ 1,2,3 Institute on Socio-Economic Studies of the Population, 117128 Nakhimovsky prospect 32, Moscow, Russian Federation \\ E-mais: ${ }^{1}$ isesp-ras@yandex.ru; ${ }^{2}$ malysheva-08@mail.ru; ${ }^{3}$ marinapparker@gmail.com
}

Received 20 March 2017; accepted 25 June 2017

\begin{abstract}
The article presents the issues of optimum utilization of labour resources in terms of sharing professional and family responsibilities caused by changing gender roles in the society and emerging of the new fathering phenomenon. The authors proceed from the assumption that promotion of business initiatives and innovations are not valuable as such but as far as they are to satisfaction of needs of the different families in view of their cultural and social priorities. The authors argue that the conduct of business should be reasonable, so that parents could successfully fulfil their family responsibilities without violation of parental rights. Otherwise, sustainability of society may be threatened. This problem is emphasized as the main one within the framework of the project on fatherhood studies in contemporary Russia. This article includes the basic results of the project.
\end{abstract}

Keywords: balance of professional and family roles, new fathering models, employees' policy, gender roles

Reference to this paper should be made as follows: Rymashevskaya, N., Malysheva, M., Pisklakova-Parker, M. 2017. Utilization of labour resources through matching professional and famility roles, Entrepreneurship and Sustainability Issues 138-149.

http://doi.org/10.9770/jesi.2017.5.1(11)

JEL Classifications: M5

1. Introduction

Acceleration in rates of development of business innovations is encouraging modern civilization to resolve the problem of overemployment in regard with the increasing intensification of labour when non-controllable time investments to chief company business produce strain among the employees and lead to conflicts in families and sometimes to family breakdown. The issue of reaching balance between employment and household responsibilities is becoming the top priority on the agenda, particularly due to emerging of the phenomenon of new fathering (Doherty et al. 1998; Wall, Arnold 2007; Finley, Schwartz 2004; Gilles 2009) and these are the intensive care practices on the part of young men, as well as their involvement in household and family duties. While women used to be expected to keep a balance between family and work, today it is also up to men to take care of this issue. Struggle for gender equality that was particularly active in the last fifty years encouraged the review of employment modes of married men. As educational and professional backgrounds of men and women is becoming equal there are less opportunities for preserving traditional division of gender roles (Khitruk 2013; Vinokurova 2015; Åberg 2015, Jankalová, Jankal 2017; Dirzytė et al. 2017; Tvaronavičienè 2016). 
The expectations regarding traditional sacrifices for the sake of family on the part of women and men's professional achievements at the expense of switching women's time and energy resources to household needs are perceived as immoral and anachronistic in the society.

Along with the achievements in the area of gender equality, another circumstances demand reviewing of balance between professional and family roles of fathers. The discoveries in the area of health care and psychology show that the role of fathers in child rearing particularly in the early development phase (up to 3 years) is dramatically underestimated. Close communication with fathers is also significant for mental and physical development of children in the school time (Mott 1993; Rohner 2004). However, the first three years of life are determining. In the last 30-40 years in some regions, particularly in the Nordic countries there were many efforts focused on making business friendly to employees with the family obligations. Many European countries followed their lead and obtained a range of state guarantees. In Russia the government also provides a range of guarantees but Russian private companies are still at the outset of development of pro-family policy with due regard to parental responsibilities of fathers. Below we will highlight some of the crucial issues of pro-family policy in Russia.

\section{Methodology}

The study was carried out in the Republic of Karelia in 2015 - 2016. Two representative samples were developed. 789 men aged 18-49 years were included in the first sample; 54 per cent of them did not have children. They were interviewed on the basis of the tool developed by Institute Promundo (USA) within the framework of the project "International Men and Gender Equality Survey" (IMAGES), which was adjusted to national conditions by a group of scholars of the ISESP RAS. The second sample included solely the fathers aged from 18 to 49 that lived in the same households with their children. Total number of respondents is 1000 . The interviewers used the Russian questionnaire including additional sections of questions that were absent in the IMAGES questionnaire. The qualitative study was carried out as well. Ten respondents took part in in-depth interviews the fragments of which are included in this article.

\section{Paternity leave: analysis}

Paternity leave is crucial in terms of fathering functions. Law of the Russian Federation includes the provision on unpaid parental leave for new fathers after the birth of a child. The leave of up to five calendar days granted upon a written request and provided for by Article 128 of the Labour Code of the Russian Federation. The duration of a leave without pay can also be determined under the agreement between the employee and an employer. The employer can grant a new father a paid leave in the cases provided for by the collective agreement. The employer may not refuse granting such a leave in case of submitting a written request by the employee.

According to our survey, after birth of the youngest child only the fourth part of fathers applied for paternity leave (80 fathers) (Figure 1); another 2,5 per cent of fathers did not work at the time and therefore they did no need a leave. 17 per cent of respondents (33 persons) out of 195 fathers who did not apply for a leave were refused the leave, and that is a law violation. 106 fathers (54.4 per cent) who could not afford to take a leave constituted a majority of this group of respondents. 23 per cent of fathers did not want to take a leave (45 persons) and 5,6 per cent of respondents did not indicate a reason due to which they did not take a paternity leave (see Figure 2). Thus, it is obvious that employers are not simply indifferent but hostile to the new fathers. 


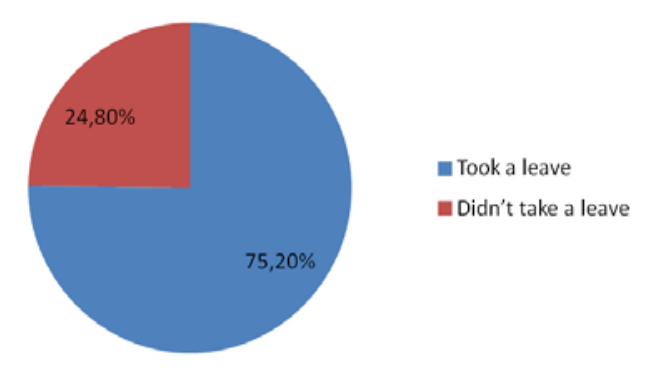

Figure 1. Proportion of fathers who took a paternity leave

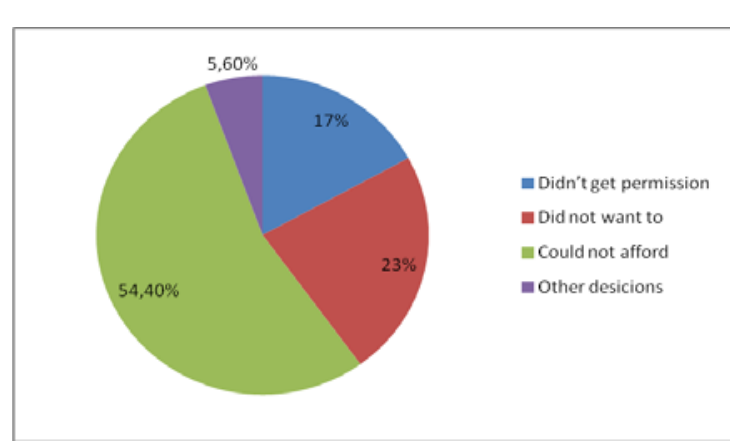

Figure 2. Reasons of refusal to take a leave

The category of respondents who took a paternity leave consists of two sub-categories: (1) men who took paid leaves and (2) men who took non-paid leaves. In both sub-categories of respondents, most fathers took leaves for the period up to one week. However, there are 72 percent of such fathers in sub-category 1 and 28 per cent in subcategory 2. Thus, most men take a part of annual paid vacation in consideration for a paternity leave. Only 24 persons could afford to take an unpaid leave. In sum, one in four women could receive help from their husbands after a childbirth within a week. Husbands of every seventh woman decided not to provide any help to them.

Awareness of men on family and legal issues. According to the survey, 52.5 per cent of respondents are not aware of legal provisions on paternity leave in Russia. Another 17.8 per cent of men think that this provision was not adopted despite the fact of its adoption in 2001. Only 29.7 per cent of men are aware of this legal provision. (See Figure 3).

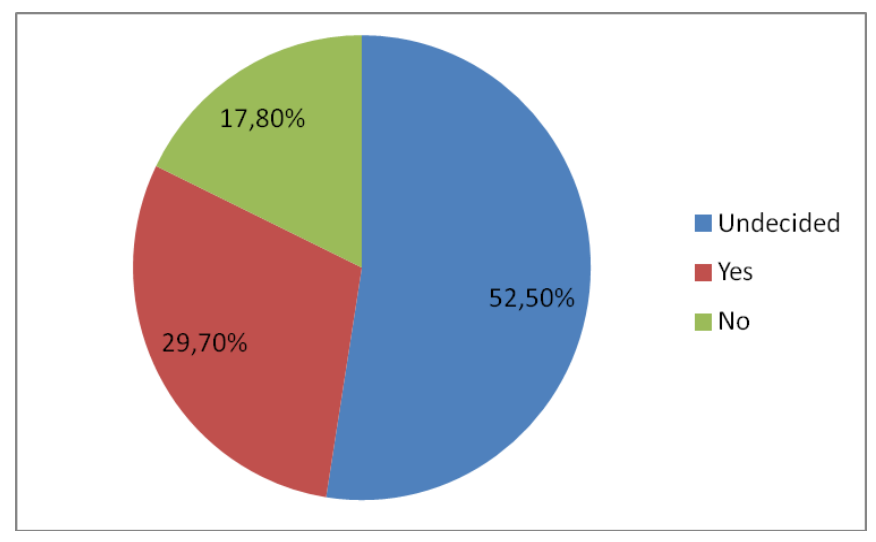

Figure 3. Proportion of men who are aware of paternity leave provisions

Along with that, respondents neither clearly distinguish between paternity/maternity leave and childcare and parental leave, nor know about the duration of leave. While giving their answers to the question on duration of paternity/maternity leave men were confusing two types of the leave and provided various periods, from a week to three years. Results of the survey showed that 19.5 per cent of respondents believe that the length of paternity leave is less than two weeks, one fourth of respondents (26.4 per cent) think that it is from one year to 18 months, and about one third of men (32.9 per cent) reported the leave duration up to three years (see Figure 4). 


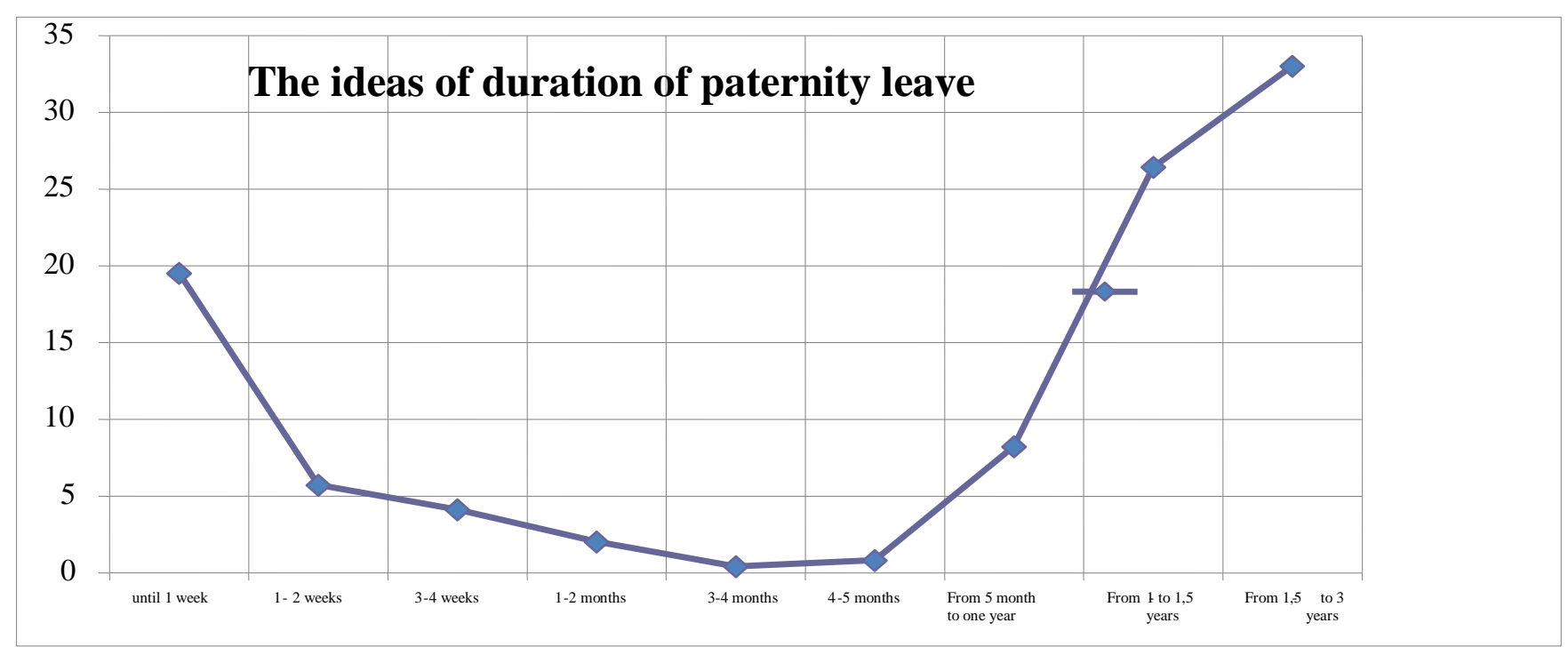

Figure 4. Men's ideas of duration of paternity leave

Below is a fragment of the in-depth interview on paternity leave:

Filmmaker, 29:

«Do we need a paternity leave? Why not? Such practice might help. However, I don't mean that this leave is necessary right after the birth... let the women care of children after they are born. Why don't they provide fathers with such opportunity when a child turns four? If fathers take care of children at this age a child could see that both parents influence her or him and contribute to her or his development. If a state supports both women and men it would encourage them; I am not sure how it would influence the country on the whole... It should be checked or tested in the future."

According to Article 256 of Russia Labour Code, maternity/paternity leave may be granted to either of the parents. The problem is that the benefit that is equal to 40 per cent of an average wage shall be paid to the insured parent in the first 18 months, and no benefits shall be provided for in the following 18 months. Maternity leave is also payable out of the Russian State Social Insurance Fund at place of employment (Article 11.1 of Federal Law No. 255-FZ "On the Provision of Sick Leave and Maternity Leave Compensation to Citizens Eligible for Mandatory Social Insurance" dated 29 December 2006). It is clear that such low payments would lead families to a significant financial loss. While women's wages in Russia are 30 per cent lower than men's salaries, it is women who usually take maternity leave.

Over fifteen years of its existence men have never applied Article 256 of Labour Code. Therefore, the provision brought discredit upon itself. The law does not contribute to fathers' involvement in child rearing nor secure the fathers' right to care of a child in the first year after her or his birth. Thus, it is still a leave for mothers and therefore there is no logic in defining it as a parental leave. Most men in Russia do not give a thought to taking advantage of this opportunity. This question is taken up in very rare circumstances, for instance in cases of a wife's higher wage. However, so far there are just a few of such cases. In our sample two per cent of respondents 
The International Journal

ENTREPRENEURSHIP AND SUSTAINABILITY ISSUES

ISSN 2345-0282 (online) http://jssidoi.org/jesi/

2017 Volume 5 Number 1 (September)

http://doi.org/10.9770/jesi.2017.5.1(11)

said that the bulk of family income consists of woman's wages and another 23.6 per cent of men reported similar salaries in their couples.

Below is another extract of the interview:

Economist, 29:

As for a maternity leave, it is natural for a woman to use it in order to take care of a child and to rear her or him due to her biological proclivity. However, today the practice of paternity leave has emerged as well but it is not as popular here as in Europe. To be honest, I would not take such a leave. I think that a man can involve when a child is a little older and it will be possible to explain things to her or him, and when she or he will be able to understand things...

In this context, and due to prevailing patriarchal attitudes, most men in Russia consider care of children aged up to three years to be a mother's duty. As few as 58.8 per cent of men in our sample believe that law shall guarantee paternity leave, 30.1 per cent of respondents are not sure of that, and 11.1 per cent of men think that it is not necessary for the state to grant paternity leave to men. One should note that the dispersed opinions remain under the existing law. Proportion of men that support a guaranteed leave is equal to the proportion of men (59.3 per cent) that are aware of the existing law including a provision on leave with children up to 3 years old. Another 40 per cent of men are not interested in provision of paternity leave and therefore they are unaware of this provision and of a leave duration.

Ignorance of the family law on the part of majority of men in Russia proves that role and meaning of fatherhood in the earliest phase of child development is underestimated in the society due to patriarchal culture and restoration of traditional values as well as lack of economic guarantees of fathers' rights. We have already mentioned that 40 per cent out of the wage is the very low amount for covering family expenses in the period of dramatic growth of family's material needs. It results in the vicious circle: men do not take a leave due to insufficient amount of benefits, and insufficient amount remains a reality due to adherence to patriarchal attitudes.

The irony is that Russia introduced parental leave before some European countries did it and that ensured the right of fathers to stay at home and to involve in child rearing after her or his birth. For instance, in UK this provision was adopted two years later. However, the situation in the UK dramatically changed since then while in Russia paternity leave provision is rather declarative. Today British fathers can take two weeks of a paternity leave and that is covered by 90 per cent of an average wage (the amount is 136,78 GBP per week) (Dermott, Miller 2015). According to exchange rate for August 2016, one GBP was equal to 83 roubles (the survey was conducted in June-July 2016), and this is equal to 11, 35 roubles per week and over 45 thousand roubles per month. While comparing these figures to the amounts calculated in the course of the survey conducted in Karelia, for July 2016 the data is the following: a net salary of 59 per cent of respondents is 30 thousand roubles per month (about 500 USD). 33.5 per cent of respondents earn from 30 to 60 thousand roubles (500 - 1,000 USD), and $60-90$ thousand roubles is the net salary of 5.7 per cent of respondents. The net salary over 90,000 roubles is earned by1.6 per cent of respondents. Thus, over a half of the men in this sample in active employment earn 280 USD less than British fathers that took a paternity leave. The earnings of one-third of respondents are the same or 15 thousand roubles more. The group with high income is very small in numbers ( 7.3 per cent). Therefore, we will not take this group into consideration. Today 40 per cent of average wages comes to 12,000 roubles per month which would amount to 24000 roubles per month in the population group with middle incomes. A decision to agree on receiving such amount would bring an average Russian family below the poverty line.

As a result, Russian fathers do not use a paternity leave while 91 per cent of British fathers take a paternity leave right after the birth of a child, and 74 per cent of the UK fathers take a paternity leave. The leave duration can be up to 18 weeks and at any period until a child turns five. The British law adopted in 2015 is even more flexible. 
Mothers can pass a part of their leave to fathers or both parents can take a leave simultaneously. Along with that, fathers have a new right to take two unpaid half-days for prenatal visits (Brien et al. 2016). Today governments in 92 countries offer paternity leave to new fathers. The leave is non-transferable, i.e. that is available only to fathers, and cannot be taken by a partner or any other relative. As many as 90 per cent of the fathers take paternity leave in Nordic countries, UK and Australia. In Germany, 30 per cent of men use paternity leave so far. The increased insurance coverage of paternity leave proves the changed attitude towards fatherhood in these countries.

Conduct of fathers in daily life. Men and society in general in Russia believe that the main responsibility of fathers is financial provision of family, and helping a partner in childcare and household work when necessary. In other words, they consider their function complementary. It is possible to make this conclusion on the ground of some statements offered for consideration to respondents. Please, see Table 1.

Table 1. Statements providing self-assessment of fathers' role in the family

\begin{tabular}{|l|l|l|l|l|}
\hline & Yes & No & Don't know & NA \\
\hline I spend too little time with my children on account of my job & 54,2 & 34,6 & 7,2 & 4,0 \\
\hline I would work less if it meant that I could spend more time with my children & 33,8 & 38,4 & 19,1 & 8,8 \\
\hline $\begin{array}{l}\text { I have the main responsibility in providing for the family } \\
\text { my wife when necessary }\end{array}$ & 81,6 & 10,9 & 3,8 & 3,8 \\
\hline
\end{tabular}

81.6 per cent of the fathers believe that their main responsibility is providing for the family. Such attitudes work in the employers' favour as they comply with business philosophy of primacy of work over family responsibilities in the life of men. Along with that, 54.2 per cent of the fathers think that they spend little time with their children due to their work, and only one third of fathers (33.8 per cent) said that they would agree to work less if it meant that they could spend more time with their children. It is also important to bear in mind that another 19 per cent of respondents chose the answer "Do not know" in regard to the question on their willingness to work less if they could spend more time with their children. Perhaps, this group of men was unable to provide a precise answer due to their strained circumstances. In case of part-time employment and guaranteed full wages, their answer would have been "yes." In this case the proportion of men that would spend more time with their children would increase up to 53 per cent and this would mean one in two fathers or even a little more.

48.9\% of men believe that their role in caring for their children and household is mostly as a helper for their wives when necessary. This opinion proves a fragmentary involvement in daily care of a family. Proportion of men that consider their care of children equal to that of their partners/wives is a little over one third of the sample or 37.7 per cent so far.

One can observe a similar situation in the previous generation of parents. The main burden of household responsibilities lay on women. 43 per cent of respondents said that their mothers took the main decisions regarding children when they and their brothers/sisters were young. 9 per cent of respondents mentioned that their fathers made decisions. Another 42 respondents said that their parents made decisions together. Time division between fathers and mothers in terms of childcare is presented in Table 2. 
Table 2. Assessment of the time spent by respondents' fathers on care of respondents

\begin{tabular}{|l|l|l|l|l|l|l|}
\hline & $\begin{array}{l}\text { Always } \\
\text { me }\end{array}$ & Usually me & Equally & $\begin{array}{l}\text { Usually } \\
\text { partner/ } \\
\text { wife }\end{array}$ & $\begin{array}{l}\text { Always } \\
\text { partner/ } \\
\text { wife }\end{array}$ & NA \\
\hline Who cares of a child on a regular basis? & 0,6 & 1,6 & 35,2 & 48,1 & 12,9 & 1,6 \\
\hline $\begin{array}{l}\text { Who stays at home with a child when } \\
\text { he/she is sick? }\end{array}$ & 0,6 & 1,3 & 7,2 & 55,7 & 32,7 & 2,5 \\
\hline $\begin{array}{l}\text { Who collects a child from school/day } \\
\text { care centre? }\end{array}$ & 3,2 & 10,0 & 34,7 & 33,8 & 9,8 & 8,6 \\
\hline $\begin{array}{l}\text { Who drives or takes the child to leisure- } \\
\text { time activities? }\end{array}$ & 1,6 & 10,2 & 34,5 & 31,6 & 10,9 & 11,2 \\
\hline
\end{tabular}

Table 2 shows that mostly mothers care of a child on a regular basis, as 61 per cent of respondents mentioned. One can observe regular division of these duties between the spouses only in one third of families (35.2. per cent). Care of children "face-to-face"' is an exception for men and their proportion is equal to only 2.2. per cent of respondents. As few as 2 per cent of fathers stayed with a sick child and 7.2 per cent of men shared this duty with their partner/wife. This behaviour reflects a patriarchal tradition according to which mothers take a childcare sick list. Employers' attitude toward men staying at home with sick children is still negative. These cultural imbalances can take place both in Russia and Western countries. Empirical observations show that when a child gets sick, managers of day care centres call mothers but not fathers in the first instance.

Regarding care of a sick child, the situation among respondents got even a little worse in recent years. Today as few as 1.3 per cent of fathers stay with sick children, compared to 2 per cent in the previous period. 7.2 per cent of fathers used to take care of a sick child together with partner compared to today's 6.4 per cent. Thus, the fathers' care in hard periods for a child's health is slightly decreasing. It would be wrong to say that the reason is the irresponsibility of modern fathers as they show their responsibility in the other aspects of child's life. It is hard to escape the conclusion that the employment situation in terms of employers' attitude to male workers with family obligations is unfavourable. If a child gets sick, fathers can neither leave their workplace, nor take a sick leave. Conservative attitudes of employers and unfriendly labour laws are obstacles preventing fathers from combining professional and family responsibilities in the situations of a child's sickness. Meanwhile, it is the situation of illness when children are in critical need of close contacts with parents in order to overcome physical pain or low spirits.

Conformity of fathers to the lack of law providing for the right to take care of a sick child or the lack of respective provisions in labour contracts is a matter of a major concern. Perhaps this situation is favourable for employers but the state should review this matter in terms of preserving health potential of a younger generation.

While majority of Russian women are traditionally employed and today it is 49 per cent of the entire employed population in the country (labour force participation rate in working age is 77 per cent), the shifting the burden of childcare and household duties on women's shoulders mean the reinforcement of social inequality. When men 
The International Journal

ENTREPRENEURSHIP AND SUSTAINABILITY ISSUES

ISSN 2345-0282 (online) http://jssidoi.org/jesi/

2017 Volume 5 Number 1 (September)

http://doi.org/10.9770/jesi.2017.5.1(11)

avoid performing family obligations referring to the traditions of the past century they defend patriarchal privileges that represent their dominant attitudes. But the most serious problem is that communicative contacts in such families are based on subordination. As a result, for a child family becomes a model of relations in society mostly built on the subordination, and to the least extent on partnership. While observing the division of household duties between parents, boys and girls apply this model to their role division in society. Authoritarian style in a family is a highway to autocracy in the society, on the labour market and in business management.

Sharp business practices in Russia, overtime exempt work schedule, weak trade unions incapable of protecting the employees' rights frequently come into conflict with models of family relationships that one may define as egalitarian. Below is a fragment of the interview with 18-year-old student living in unregistered union, without children:

I think that parenting depends mostly on human factor but not on a country. There are people with various attitudes and characters. For instance, some people do not plan to have their own family. They prefer to focus their efforts on career and on the hobbies like gambling. I think that it is not because of the country. It is due to a person. Perhaps the country influences the fathering in a way because we all live in a post-Soviet state where racketeering and illegal business bankruptcy are common. Sometimes it is obvious that people just gave up ... I don't think that there are any positive perspectives in the future, I see just negative things ahead. There are no conditions for a real fathering in the country. I am convinced though that there are people who are able to create favourable conditions for themselves in spite of the different obstacles.

According to the historical experience of different countries, commitment of governments to principles of familyfriendly policies in business and the labour market can cause involved fatherhood. The question of employees with family responsibilities has been on the agenda on various levels in our society but they placed special emphasis on the mothers so that parenthood was equalized to motherhood. As for fathers, the society still considers the issue of balance between family and work to be a personal problem.

Meanwhile, Russian fathers passed through the course of shocking therapy due to the process of family nuclearization during the latter half of the twentieth century, and retreat of governments from a range of social programs that resulted in dramatic decrease in number of child care centres. The fathers had to get adjusted to completely new circumstances of child rearing with a scarce assistance of relatives and the state. Along with that, men were supposed to continue performing their obligations of a breadwinner and provide economic support to family. In addition, men's partners/wives expected that men would become involved fathers and invest their leisure time to the family (quantitative aspect), as well as add up a new content to their family relations and express their care and emotional attachment to partner and children (qualitative aspect).

In order to reach the balance, fathers with low and middle incomes try to reach informal agreement with their employers for obtaining flexible working schedule (starting a working day later or leaving workplace earlier, taking a day off, etc.). Fathers with higher incomes struggle for higher wages in order to hire a baby-sitter or to have an opportunity of paying for a private childcare centre. However, so far Russian employers view measures of the pro-family policies as the sources of extra expenses but not as the ways of recruiting young employees and holding of a highly skilled professional in the company.

What is most notably for Russia, policy makers do not realize specific nature of the situation in Russia that forces fathers to be more active. This specific nature implies two points: the first point is a higher educational level of women in Russia in comparison with men. There are 55 per cent of women among employed university-educated population. The second point is the rapid health deterioration of expectant mothers and children. Studies show that today the health potential of younger children is much worse than that of previous generations. According to 
The International Journal

ENTREPRENEURSHIP AND SUSTAINABILITY ISSUES

ISSN 2345-0282 (online) http://jssidoi.org/jesi/

2017 Volume 5 Number 1 (September)

http://doi.org/10.9770/jesi.2017.5.1(11)

corresponding member of the Russian Academy of Sciences Natalia Rimashevskaya, "over one third of children are born unhealthy or they become ill immediately after birth without undertaking treatment." (Rimashevskaya 2010). Proportion of children with disabilities is growing rapidly, as well as number of highly allergic children. Along with that, health of expectant and nursing mothers is deteriorating. Today their health is worse than that of expectant mothers of previous generations. Thus, there is an urgent need in the qualitative and quantitative increase in fathers' involvement in care of children and partners/wives. The problem should be resolved via the implementation of multi-agency approach. The health care system by itself is insufficient. A need in intensification of factors beyond the health care field makes inevitable flexibilization of working hours for both parents and the recognition of critical importance of involved fatherhood in reproductive labour with adequate compensation for loss of earnings in the early postnatal period ( $80-100$ per cent of a principal monthly salary).

The Roadmap of "The Concept of State Demographic Policy of the Russian Federation for the Period Until 2025" includes a range of key measures aimed at combining professional and child care obligations by parents, among them availability of pre-school education (Measure 4) and formation of the environment that is friendly to the employees with family obligation (Measure 6). In the latter case, we are referring to recommendations developed for a draft of a general agreement between national trade union associations, national employers' unions and the Russian Government for 2017-2019. However, there is a need in the laws to be adopted by the Ministry of Labour and Social Protection which would establish flexible forms of employment for parents with small children, for instance part-time work, split working day, shortened working day, flexible schedule, etc., as well as other benefits in the labour field in view of gender differences of employees.

Thus, in Russia the need in encouraging fathers' involvement in the first days of a child's life is not just an issue of gender equality or expanding new parental patterns but also a question of preserving population health and resolving pressing population problems in terms of improvement of genetic resources.

Transition to involved fatherhood will demand generating a new interpretation of the former concepts. For instance, recognition of father and fathering would demand the definition of a far wider range of obligations in terms of child care. This is due to the idea that fathers should involve in child birth from the period of partner's pregnancy and delivery, and fathers should respond to a child's needs from the first days of her or his life.

So far, the society is too far from realizing necessary vector of development. The comments made by the member of the Russian Civic Chamber and the "Federal Fathers' Union" Vladimir Slepak prove that. He said the following: "In the current situation, Russian families with children have become social outcasts and most of them live below the poverty line. Child abandonment is caused by this intolerable situation. For instance, in Russia in the 2011 - 2015 timeframe a number of homeless orphans increased from 70 thousand to 128 thousand people. Annually in Russia 50,000 fathers and mothers are deprived of parental rights and 44,000 parents lose their children due to the substance abuse.' Slepak also makes a special emphasis on the problems of disabled children and inaction of the institutions of social and medical expert examination due to which thousands of children were deprived of their benefits required by law. Lastly, he mentioned problems of divorced spouses. For instance, the highest divorce rate was indicated in 2015 when the separation factor was 540 divorces came for 1,000 marriages (“Union of Fathers”).

A problem of institutional ensuring of fathers' opportunity of being involved 'here and now', engaged in household duties and child rearing is becoming critical in Russian society today. A solution may be assuming profamily attitudes by the government and top managements of business structures otherwise the quality of new labor resources will fall dramatically. At least two emergency measures are necessary to implement. The first above mentioned measure is establishing of the system of benefits for fathers with family responsibilities. The second measure is quite sensitive and it might demand dramatic political changes. This is the culture of employment. 
The culture of employment. The culture of employment makes a serious impact on the fathers' ability to reach a balance between professional and family roles. This is something more than family-friendly policy on the part of employers. It implies fathers' psychological comfort when it is necessary to discuss family obligations with heads of companies and colleagues in order to leave the workplace earlier for collecting a child from school or for staying with a sick child at home. Fathers do feel uncomfortable in such situations due to the prevailing attitude regarding the importance of overtime work that demonstrate commitment to the company. Therefore, men rarely express their dissatisfaction with frequent extra work assignments though there is a tendency of internal resistance to practices of long working hours among young men. They seem to be dissatisfied with working conditions.

As a rule, company managers do not make open statements on any established privileges for parents with small children. Employers believe that providing an ad-hoc information is enough for their understanding of the issue. The principleposition of employers is not to announce pro-family policy though they may declare support mechanisms for their employees in mass media. As a result, employees are insecure in most situations when they need to make decisions in favor of their family duties. Often employers insist that men with family duties do not make any demands, though they know for sure that men do not make demands due to their low awareness of the employer's policies. At any rate, employers prefer an unofficial deal instead of open procedures. This applies to cases of emergency that put men to risk of new employment stress situations.

Super mortality among men of working age in Russia is well known. The widely accepted causes are substance abuse, traumatism, traffic accidents, violent acts and low wages. We believe that a crucial factor of male mortality is unbalanced workload caused by the need in facing severe competition on the labour market and meeting increasingly stringent fathering requirements, particularly if a partner's educational background is similar or higher (Zdravomyslova 2015).

\section{Conclusions: obstacles to establishing balance between family and professional roles among fathers}

To conclude, we would name several reasons why fathering roles remain outside the area of mainstream politics in terms of the state or business:

1) Lack of public discussions on new fathering in mass media and popular literature. Discussions on new fatherhood are still rare in the Russian society. This is an underexposed issue in the media and popular literature, and publications on these issues appeared in sociological articles as recently as 10-15 years ago. These articles describe the ways of communication of fathers and children having discursive correlation with gender equality issues. However, value of fatherhood, its personalization and privacy in terms of freedom of choice and powerful force that can transform demographic characteristics of the society and the quality of new generations of children is not on the agenda.

2) Insufficient information about European situation in terms of the new fathering culture with legislative and institutional changes in public-private sector. There is more information available about the situation in the Nordic countries as they have a longer history and tradition of implementation of social and economic measures aimed at the fathers' involvement in various areas of family life. The fact that there are experienced scientists in these countries, who have conducted the multi-year researches on the issue, has a crucial role on the advancement of these studies in Russia. Along with that, number of NGOs that have been promoting pro-fathering policies and introducing fathering practices became well-known in northern regions of Russia within the framework of crossborder cooperation. 
3) Deficit of the researches in Russia on fathering and fatherhood at the regional and national scale and most importantly the absence of statistical series of research, that are necessary for drawing reliable conclusions on the changes in fathers' parenting practices.

4) Like European countries, Russian society is not prepared to differentiate between parenting and fathering. For instance, parenting closely relates to men's role of a breadwinner. In contrast, fathering implies specific personal characteristics distinguishing between individual fathers. However, personal characteristics are determined in historical and cross-national perspective and depend on a form of a state structure. That will always be a source of practices divergence in establishing the balance between family and professional roles even under globalization of labour employment regimes.

\section{References}

Åberg, P. 2015. Civil society and biopolitics in contemporary Russia: The case of Russian “Daddy-Schools”, Foucault Studies, $20,76-95$.

Brien, O.; Moss, M.; Koslowski, P.; Daly, A. 2016. Country reports: United Kingdom, in P.Moss (ed). International Network on Leave Policies and Research. London. Department for Business, Innovation and Skills, www.leavenetwork.org/

Dermott E., Miller T. 2015. More than sum of its parts? Contemporary Fatherhood policy, practice and discourse, Family, Relationships and Societies 4(2): 183-195.

Dirzyte, A.; Rakauskienė, O. G.; Servetkienè, V. 2017. Evaluation of resilience impact on socio-economic inequality, Entrepreneurship and Sustainability Issues 4(4): 489-501. https://doi.org/10.9770/jesi.2017.4.4(7)

Doherty W., Kouneski E.F., Erickson M.F. 1998. Responsible Fathering: an overview and conceptual framework. Journal of Marriage and Family 60(2): 277-292. http://www.jstor.org/stable/353848

Finley G., Schwartz S. 2004. The father involvement and nurturant fathering scales: retrospective measures for adolescent and adult children, Educational and Psychological Measurement 64: 143-144.

Gilles V. 2009. Understandings and experiences of involved fathering in the UK: exploring class dimensions, The ANNALS of the American Academy of Political and Social Science 624(1): 49-60. https://doi.org/10.1177/0002716209334295

Jankalová, M.; Jankal, R. 2017. The assessment of corporate social responsibility: approaches analysis, Entrepreneurship and Sustainability Issues 4(4): 441-459. https://doi.org/10.9770/jesi.2017.4.4(4)

Khitruk, E.B. 2013. Philosophical background of the formation of the phenomenon of the "Absent Father” in the contemporary culture, Herald of the Tomsk State University 368: 54-59.

Mott F.L. 1993. Absent Fathers and Child Development. Emotional and Cognitive Effects at Ages Five to Nine. Ohio State University, p. 4-5.

Rimashevskaya N. M. 2010. Radical Changes of the Negative Health Trend in Russia, Narodonaselenije 1: 4-10.

Rohner, R. P. 2004. The Parental "Acceptance-Rejection Syndrome": Universal Correlates of Perceived Rejection American Psychologist 59(8): 830-840. URL: http://dx.doi.org/10.1037/0003-066X.59.8.830

The “Union of Fathers”, established in Russia. URL: http://www.er-duma.ru/news/v-rossii-sozdan-soyuz-ottsov/

Tvaronavičienè, M. 2016. Start-ups across the EU: if particular tendencies could be trace, Entrepreneurship and Sustainability Issues 3(3): 290-298. https://doi.org/10.9770/jesi.2016.3.3(6)

Vinokurova, N. 2015. Sustainable entrepreneurship and women in science and education: gender equality, gender inequality, Entrepreneurship and Sustainability Issues 2(4): 220-232. https://doi.org/10.9770/jesi.2015.2.4(5) 
Wall G., Arnold, S. 2007. How involved is involved fathering? An exploration of the contemporary culture of fatherhood, Gender and Society 21(4): 508-527. https://doi.org/10.1177/0891243207304973

Zdravomyslova, O. 2015. Looking for balance: the issues of balance of the family and work in the estimates of men and women, Present and the Future of the Family in the Changing World. Moscow, Institute on Socio-Economic Studies of the Population 2015, pp. 208-2018.

Natalia RIMASHEVSKAYA, corresponding-member of the Russian Academy of Sciences, Vice Director of the Institute on SocioEconomic Studies of the Population, Moscow, Russia. Under her supervision over 50 people defended doctoral thesis across the whole country, Eastern Europe and the other parts of the world. He outstanding longitudinal research study in Taganrog city (the South of Russia), which she carried out over than 50 years on the different aspects of life of the population, is well known all over the world. She is also the Chief Editor of the magazine "Narodonaselenije" and the founder of the first Center for Gender Studies in the Russian Federation. Her primary research interests are: economic inequality in the society and social mobility, health issues, demographic development of the population, values and strategies of house holdings in economic crises, gender equality and the future of the family.

Marina MALYSHEVA, Dr. of Economics, Leading Research Fellow at the Institute on Socio-Economic Studies of the Population, Moscow, Russia. She also defended her thesis in Sociology and within 35 year was doing interdisciplinary research on social efficiency of women's professional labor, gender roles and attitudes in family and society, women's migration and women's reproductive labor. She has done a pioneering research on genealogy of Russian families throughout the $20^{\text {th }}$ century and was one of the primary contributors into the development of qualitative methodology in sociology in Russia. Currently she is also making analytical analysis of the international data on the development of STEM education for women. The current research interests: childhood as a resource of the human potential development, different forms of parenting, fatherhood and motherhood.

ORCID ID: orcid.org/0000-0003-3551-1807

Marina PISKLAKOVA-PARKER, Dr. of Sociology, Senoir Research Fellow at the Institute on Socio-Economic Studies of the Population, Moscow, Russia. The Chair of the Women's Center for the Prevention of Violence ANNA, Board member of "WAVE" (Women against Violence Europe). Main interests: gender equality, violence against women, fatherhood, women's rights.

ORCID ID: orcid.org/0000-0003-3551-1807

Register for an ORCID ID:

https://orcid.org/register

Copyright (C) 2017 by author(s) and VsI Entrepreneurship and Sustainability Center

This work is licensed under the Creative Commons Attribution International License (CC BY).

http://creativecommons.org/licenses/by/4.0/

c) (i) Open Access 